\title{
1-(Benzoylamino)-3-methylimidazolium Chlorochmmate (BAMICC), a New Selective and Mild Reagent for the Oxidation of Allylic and Benzylic Alcohols
}

Yolanda Martinez, María A. de las Heras, Juan J. Vaquero, José L. Garcia-Navio and Julio Alvarez-Builla ${ }^{\star}$

\author{
Departamento de Quimica Organica. Universidad de Alcalá 28871-Alcalá de Henares, Madrid Spain
}

\begin{abstract}
A new mild chromum(VI) oxidizing reagent, the 1-(benzoylammo)-3-methylimidazolium chlorochromate (BAMICC) has been prepared as a stable yellow-orange solid which selectively oxidizes allylic and benzylic alcohols, including those bearing basie nitrogens, to carbonyl compounds.
\end{abstract}

Prior to 1975 the principal oxochromium-amine reagent used for the conversion of alcohols to carbonyl compounds was the Collins reagent ${ }^{1}$ and related systems based on the chromium trioxide-pyridine complex first described by Sarett ${ }^{2}$ Since the introduction by Corey and Suggs of the pyridinium chlorochromate (PCC) ${ }^{3}$, complexes of chlorochromate with ligands such as 2,2 -bipyridine, ${ }^{4} 4$-(dimethylamino)pyridine, ${ }^{5} 1,8$ naphthyridine, ${ }^{6}$ pyrazine ${ }^{6,7}$ and trialkylamines ${ }^{8}$ inter alia have been reported In general, these aminechlorochromate complexes are milder than the acid-based reagent systems and show various degrees of selectivity towards the oxidation of alcohols to carbonyl compounds depending on the donor strength of the associated amine ligand ${ }^{80.9}$ However, in most cases oxidation still remains difficult on substrates containing basic nitrogens, since exchange may occur with the oxidant to give substrate-chromium complexes. ${ }^{10}$
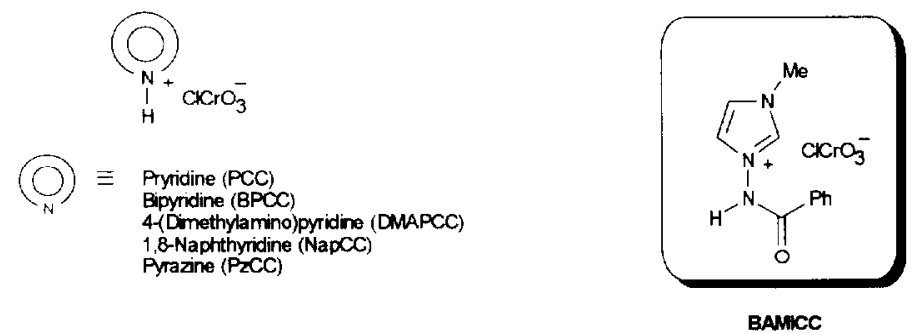

Scheme 1

Our interest in new synthetic applications of 1 -(acylamino)cycloimmonium salts ${ }^{11,12}$ led us to explore the preparation and oxidant properties of chlorochromate salts which incorporate an $\mathrm{N}$-aminide as a ligand for the first time and here we report our initial results in the use of 1-(benzoylamino)-3-methylimidazolium chlorochromate (BAMICC) as a new chromium(VI) complex oxidant.

Of the various $\mathrm{N}$-amınides explored, a combination of 1 -methylimidazolc as heterocycle and the benzoyl group as acyl moiety gave a nonhygroscopic and air-stable chlorochromate salt which was easily prepared from 
the $\mathrm{N}$-aminide 2 and $\mathrm{CrO}_{3}$ in the presence of $\mathrm{HCl}$. Like other complexes, BAMICC does not dissolve appreciably in organic solvents. The selectivity of this reagent was indicated by the absence of oxidation of primary and secondary alcohols when compared to the slow oxidation of allylic or benzylic alcohols. Thus treatment of 2-phenylethanol or 2-cyclohexylpropanol (see Table, entries 1 and 2) in refluxing $\mathrm{CH}_{2} \mathrm{Cl}_{2}$ with 5.0 equiv of BAMICC for $48 \mathrm{~h}$ leads to recover unchanged the alcohols This result contrasts with those obtained with benzylic alcohols (entries 3-5) which are oxidized in $\mathrm{CH}_{2} \mathrm{Cl}_{2}$ to the corresponding aldehydes or ketone using 1.5 equiv of the complex. When a higher excess of the oxidant was employed a reaction rate enhancement was observed within the first two hours but the reaction was completed only after $15 \mathrm{~h}$ at reflux temperature (entry 3 ). Under similar conditions allylic alcohols are also oxidized to the corresponding $\alpha, \beta$ unsaturated aldehydes in good yields although the oxidation of Z-2-hexenol resulted in extensive geometric isomerization of the double bond either using 1.5 or 5 equiv of the reagent (entry 6)

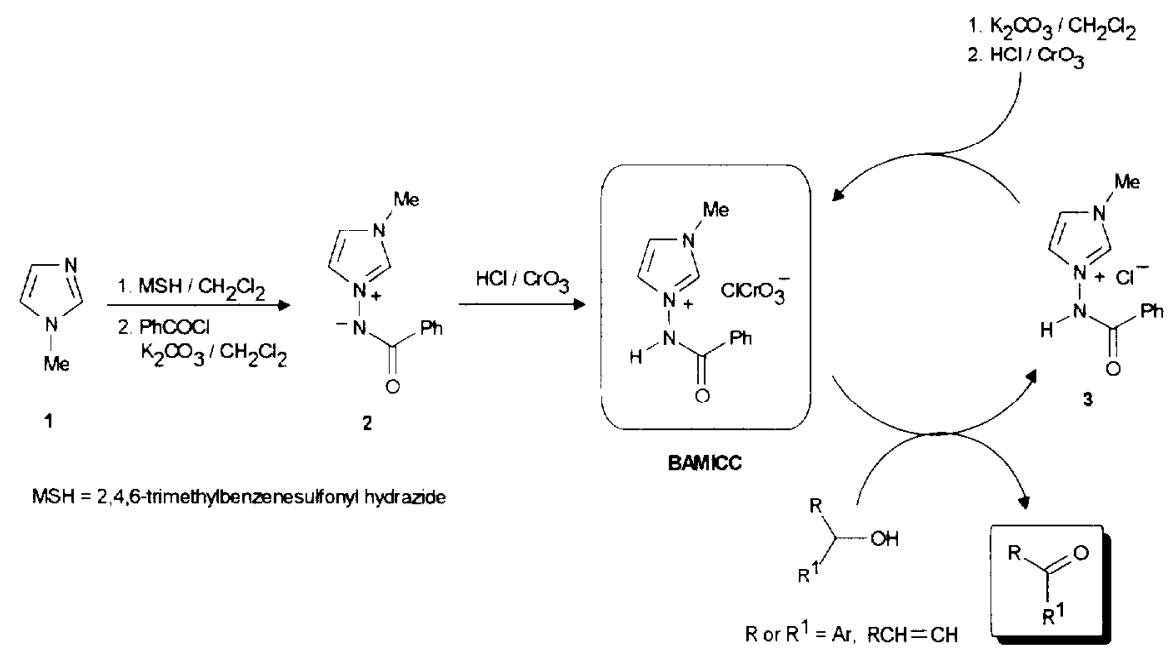

Scheme 2

A remarkable utility of BAMICC was found in the oxidation of substrates bearing basic nitrogens (entries 7-9). Substrates such as 2- or 3-pyridylcarbinol proved to be more reactive than benzyl alcohol and complete conversion to the corresponding aldehydes were obtained using 1.5 equiv after $8 \mathrm{~h}$. Under similar conditions other previously reported chromium(VI) complexes failed to give this conversion due to above mentioned exchange problems. ${ }^{10}$

Two diols were also tested for illustrating the selectivity of this reagent. The oxidation of 1-phenyl-1,3propanediol (entry 10) with 1.5 equiv afforded the ketone in $75 \%$ yield, whereas the phenylglyoxal was the main reaction product $(58 \%)$ obtained when the $)$-phenyl-1,2-ethanediol (entry 11$)$ was subjected to oxidation. In the latter case the initial formation of the ketone presumably activates the remaining primary alcohol group.

It should be noted that a further advantage of this reagent is that at the end of the oxidation process the imidazolium salt 3 produced can be easily recovered and reused to obtain the BAMICC complex through the $\mathrm{N}$-aminide 2 (Scheme 2) 
Table. Oxidation of Alcohols to Carbonyl Compounds with BAMROC.

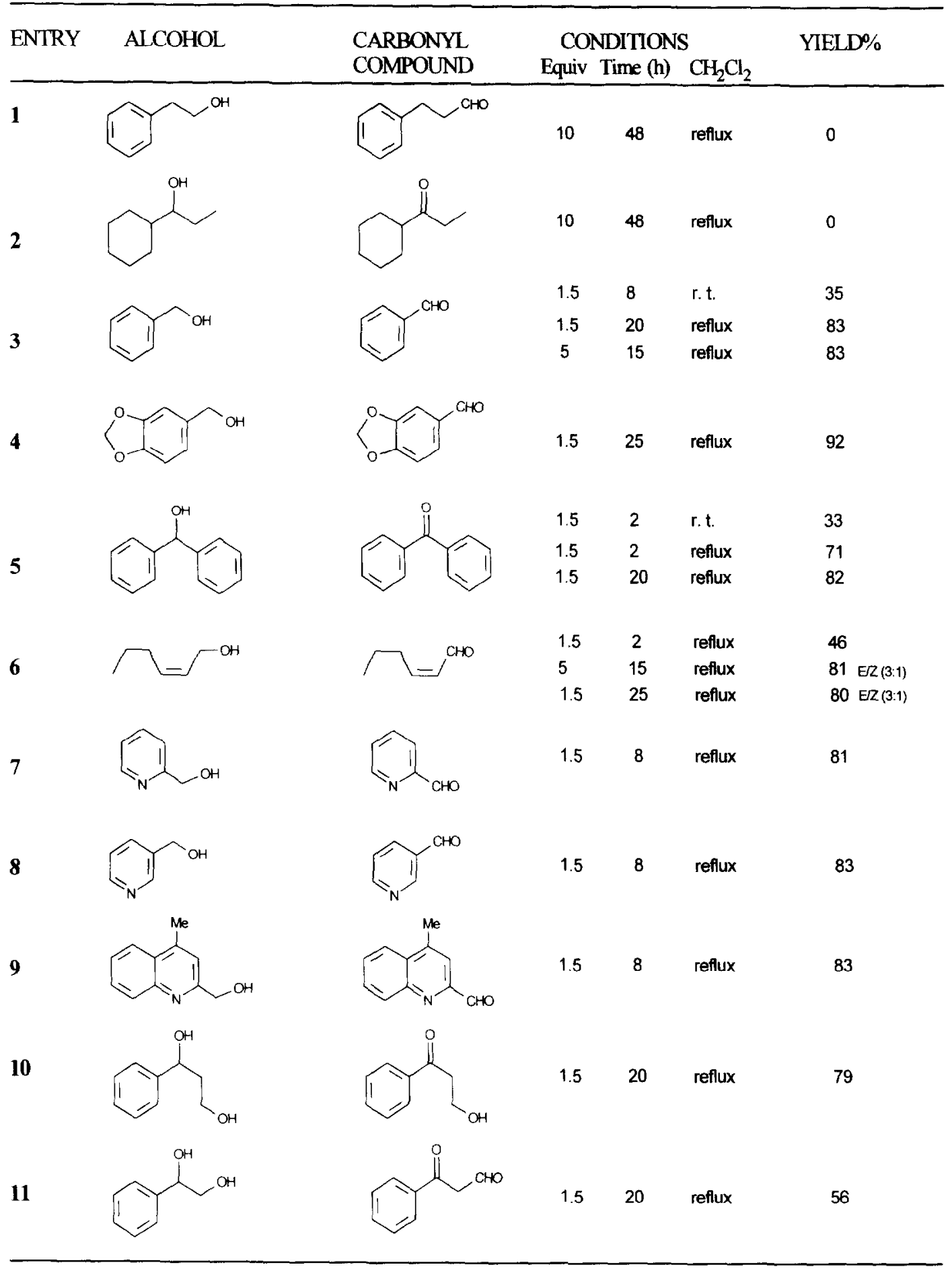


The BAMICC reagent ${ }^{13}$ was prepared as follows: To a stirred solution of $\mathrm{CrO}_{3}(1 \mathrm{~g}, 10 \mathrm{mmol})$ in $6 \mathrm{~N} \mathrm{HCl}$ $(10 \mathrm{ml})$, a solution of the $\mathrm{N}$-aminide $2^{11}(2 \mathrm{~g}, 10 \mathrm{mmol})$ in $20 \mathrm{ml}$ of $6 \mathrm{~N} \mathrm{HCl}$ was slowly added. The reaction mixture was cooled to $0^{\circ} \mathrm{C}$ and the yellow-orange solid formed was collected by filtration, washed with water and dried under vacuo (yield $3.1 \mathrm{~g}, 92 \%$ ). In a typical oxidation procedure the reagent was suspended in $\mathrm{CH}_{2} \mathrm{Cl}_{2}(5 \mathrm{ml}$ for each $0.5 \mathrm{mmol})$ and the alcohol $(0.5 \mathrm{mmol})$ was added. The mixture was refluxed until the alcohol was consumed (see table) and then diluted with dry ether $(10 \mathrm{ml})$. The supernatant was decanted and the insoluble residue washed with dry ether $(3 \times 5 \mathrm{ml})$. The combined organic solution was passed trough a short column of celite, and the solvent was removed under reduced pressure. The carbonyl compound was purified by distillation or column chromatography. The $\mathrm{N}$-aminide 2 was recovered by treatment of the insoluble residue with $\mathrm{K}_{2} \mathrm{CO}_{3}(0.55 \mathrm{~g}, 4 \mathrm{mmol})$ in $\mathrm{CH}_{2} \mathrm{Cl}_{2}(15 \mathrm{ml})$. After stirring for $4 \mathrm{~h}$, the organic phase was separed by filtration and 2 was isolated in a $83 \%$ yield by simple removal of the solvent

In summary, the use of BAMICC is a cheaper and cleaner alternative to other chromium(VI) complexes for the oxidation of allylic and benzylic alcohols, including those bearing basic nitrogens. Further studies of the oxidant properties of this and related reagents are in progress in our laboratory and will be reported on due course

Acknowledgements. The authors are grateful for a grant (MAH) received from Ministerio de Educacion y Ciencia and for financial support from Comisión Interministerial de Ciencia y Tecnología (CICYT, project PB90-0284).

\section{REFERENCES AND NOTES}

1. Collins, J. C.: Hess, W. W.; Frank, F. J. Tetruhedron Lett. 1968, 3363.

2. Poos, G. I, Arth, G. E.: Beyler, R. E.; Sarett, L. H. J. Am. Chem. Soc 1953, 75, 422

3. (a) Corey, E., Suggs, J. W. Tetrahedron Lett. 1975, 2647. (b) For a review of PCC see: Piancatelli, G Scettri. A.; D'Auria, M Synthesis, 1982, 245

4. Guziec, F. S ; Luzzio, F. A Synthesis, 1980, 691

5. Guziec, F S ; Luzzio, F, A J. Org. Chem. 1982, 47, 1787

6. Davis, H. B., Sheets, R. M., Brannfors, J. M., Paudler, W. W., Gard, G. L. Heterocycles, 1983, 20,2029

7. (a) Davis, H. B. Sheets, R. M., Paudler, W. W., Gard, G. L., Heterocycles, 1984, 22, 2029. (b) Doad, G. J. S. J. (hem Res. (S), 1988, 270.

8. (a) Rao, C G : Radhakrisna, A S.; Singh, B. B ; Bhatnagar, S P. Synthesis, 1980, 808. (b) Santaniello, E.; Milani, F. Casati, R. Synthesis, 1983, 749. (c) Acharya, S P.; Rane, R. A Synthesis, 1990, 127

9. Guerrero, A. F. Kim, H. J., Schlecht, M. F. Tetrahedron Lett. 1988, 29, 6707.

10. (a) Ley, S. V., Madin. A. Oxidation Adjacent to Oxigen of Alcohols by Chromiun Reagents in Comprehensive Organic Synthesis; Trost, B., Fleming, 1. Eds. vol. 7, p. 251-289, Pergamon Press, Oxford, 1991. (b) Luzzio, F. A.. Guziec. F. S. Org. Prep. Proced. Int. 1988, $20,535$.

11. Heras, M. A.: Molina, A.; Vaquero, J. J., Garcia-Navio, J. L.; Alvarez-Builla, J. J. Org. Chem., 1993, 58 , 5862.

12. Heras, M. A.; Vaquero, J. J., Garcia-Navio, J. L., Alvarez-Builla, J. Tetrahedron Lett. 1995, 3, 455

13. BAMICC: yellow-orange powder; $\operatorname{mp} 113-114^{\circ} \mathrm{C}$, IR $(\mathrm{KBr}) v_{\max } 3103,2954,1634,1514,1273 \mathrm{~cm}^{-1}$ 'H NMR (300 MHz, DMSO-d 6 ) $\delta 12.80$ (bs, 1H), 9.46 (s, lH), $7.9(\mathrm{~m}, 3 \mathrm{H}), 7.77$ (bs, 1H), 7.6-7.5 (m, $3 \mathrm{H}), 3.91(\mathrm{~s}, 3 \mathrm{H}) \mathrm{ppm}$

(Received in UK 28 July 1995; revised 19 September 1995; accepted 22 September 1995) 